\title{
Detection of Intestinal Parasites Transmitted Mechanically by House Flies (Musca domestica, Diptera: Muscidae) Infesting Slaughterhouses in Khartoum State, Sudan
}

\section{Ahmed Mohammed Al-hassan Ibrahim ${ }^{1 \#}$, Hafiz Hassan Shebeir Ahmed ${ }^{2 \#}$, Rehab AbdElgadir Adam ${ }^{3 \#}$, Ayman Ahmed ${ }^{4}$ and Arwa Elaagip ${ }^{5 *}$}

${ }^{1}$ Bahri Military Hospital, Khartoum, Sudan

${ }^{2}$ White Nile Malaria Control Program, Ministry of Health, White Nile State, Sudan

${ }^{3}$ Alrebat University Hospital, Khartoum, Sudan

${ }^{4}$ Institute of Endemic Diseases, University of Khartoum, Sudan

${ }^{5}$ Department of Parasitology and Medical Entomology, Faculty of Medical Laboratory Sciences, University of Khartoum, Sudan

${ }^{\#}$ These authors contributed equally to this work.

*Corresponding author: Arwa Hassan Elaagip, Department of Parasitology and Medical Entomology, Faculty of Medical Laboratory Sciences, University of Khartoum, Khartoum, Sudan

\begin{abstract}
Background: The housefly, Musca domestica, is a common household pest known to transmit human diseases like pathogenic bacteria, protozoa, metazoan, fungi and viruses. Apart from they are also responsible for transmitting intestinal parasites, which when outbreaks occur, could wreak havoc on both man and animals. The importance of house fly in disease transmission prompted this study to investigate the presence of intestinal parasites transmitted mechanically by houseflies that infested slaughterhouses in central markets in Khartoum state, Sudan.
\end{abstract}

Methods: Thirty fly sticky ribbons were placed inside random slaughterhouses in three central markets in Khartoum, Khartoum North and Omdurman between May and June 2018. Collected flies were preserved in tubes filled with normal saline and kept in $-20{ }^{\circ} \mathrm{C}$, then morphological identification of the collected house flies was conducted using standard identification keys. Examination and identification of intestinal parasites transmitted mechanically by $M$. domestica flies was conducted using microscope and standard keys.

Results: A total of 684 house flies were collected and examined during the course of this study. Out of this number, twenty $(2.9 \%)$ house flies were found to harbor intestinal parasites from all sites. In the central market of Khartoum, 300 house flies were examined out of which $4.7 \%$ were infected $(n=14)$.
Out of the 260 house flies examined in Khartoum North, $2.3 \%$ were infected $(n=6)$ while a total of 124 house flies were examined in Omdurman slaughterhouses with $18.1 \%$ infected. The identified intestinal parasites were Entamoeba coli cyst, Entamoeba histolytica/dispar cyst, Giardia lamblia flagellate, Giardia lamblia cyst, Hymenolepis nana egg and Taenia species egg with infectivity rates of $33.3 \%, 19 \%$, $19 \%, 14.3 \%, 9.5 \%$ and $4.8 \%$ respectively of the total house flies collected.

Conclusion: Findings of this study indicate a relatively high infectivity rate in the disease vectors. Since this research detected this high rate of gastrointestinal parasites in the flies, their role in disease transmission cannot be over emphasized. This highlight the prevalence of such disease like diarrhea in Khartoum. Hence, there is need to raise awareness on the need to improve hygiene and sanitation in the communities where these slaughterhouses are situated so as to prevent a possible outbreak.

\section{Keywords}

Intestinal parasites, House fly, Musca Domestica, Khartoum State, Sudan

Citation: Ibrahim AMA, Ahmed HHS, Adam RA, Ahmed A, Elaagip A (2018) Detection of Intestinal Parasites Transmitted Mechanically by House Flies (Musca domestica, Diptera: Muscidae) Infesting Slaughterhouses in Khartoum State, Sudan. Int J Trop Dis 1:011.

Accepted: November 17, 2018; Published: November 19, 2018

Copyright: (C) 2018 Ibrahim AMA, et al. This is an open-access article distributed under the terms of the Creative Commons Attribution License, which permits unrestricted use, distribution, and reproduction in any medium, provided the original author and source are credited. 


\section{Introduction}

The housefly, Musca domestica Linnaeus, 1758 is one of the most synanthropic and cosmopolitan flies found in the tropics [1]. They are commensal on humans, poultry, and animals, and spread food-borne illness [2,3]. They are considered as important mechanical vector for a number of pathogenic bacteria, protozoa, metazoan, fungi and viruses [4]. Pathogens are picked-up by the flies from garbage, sewage and other sources of filth on their mouthparts and other body parts, and then transferred to human and/or animal food [5]. Houseflies faecal, sponge feeding and regurgitating behavior facilitates food-borne diseases transmission [6]. The most common diseases that are transmitted mechanically by the houseflies include, but not limited to poliomyelitis,cholera, typhoid fever, parasitic worms, bacillary dysentery, trachoma virus, epidemic conjunctivitis, shigellosis, salmonellosis and enteric infections $[7,8]$. Most of these pathogens may live inside and on $M$. domestica external surface for 5 - 6 hours and to 35 days post-infestation $[8,9]$. Transmission takes place when the house fly makes contact with people or their food. Most of the diseases can alsobe contracted through contaminated food, water, air, hands and person-to-person contact [10]. The role of house flies as mechanical vectors of infectious diseases in humans has been suggested by the results of many experimental and field studies [1-16].

This study was conducted to identify the intestinal parasitic pathogens transmitted mechanically by house flies in slaughterhouses in three central markets of Khartoum state, Sudan.

\section{Methods}

\section{The study site}

Khartoum state is located in the northern part of central Sudan and is the capital of the country $\left(15^{\circ} 38^{\prime}\right.$ $\mathrm{N}, 032^{\circ} 32^{\prime} \mathrm{E}$ ) [17] (Figure 1). The total area of the state is $28000 \mathrm{~km}^{2}$; it is divided by the Blue Nile, White Nile and River Nile into three greater administrative areas: Khartoum North, Khartoum and Omdurman. These areas differ in their topography, agriculture and socioeconomic activities [18]. The state is composed of seven localities. The estimated population of Khartoum state is 8 million [17].

\section{Collection of the flies}

The flies were collected between May and June 2018 using 30 fly ribbons at slaughterhouses across the three central markets in Khartoum, Khartoum North and Omdurman cities. The sticky ribbons used were non-toxic passive traps (Revenge Fly Catcher ${ }^{\circledR}$ ) placed inside or as close to the entrance of the selected slaughterhouses as possible. Date of placement was recorded in each randomly collected site accordingly. In order to increase fly trapping surface, every attempt was made to place the ribbons vertically and away from walls and direct sunlight [4]. The minimum and maximum temperature during the collection period was $25^{\circ} \mathrm{C} / 46^{\circ} \mathrm{C}$.

Forceps were used to place individual flies from each slaughterhouse ribbons into sterile collection tubes and $3 \mathrm{ml}$ of normal saline was added to each tube. The forceps were thoroughly cleaned with $70 \%$ alcohol and completely air dried between each fly and another to decrease the likelihood of cross-contamination. Then,
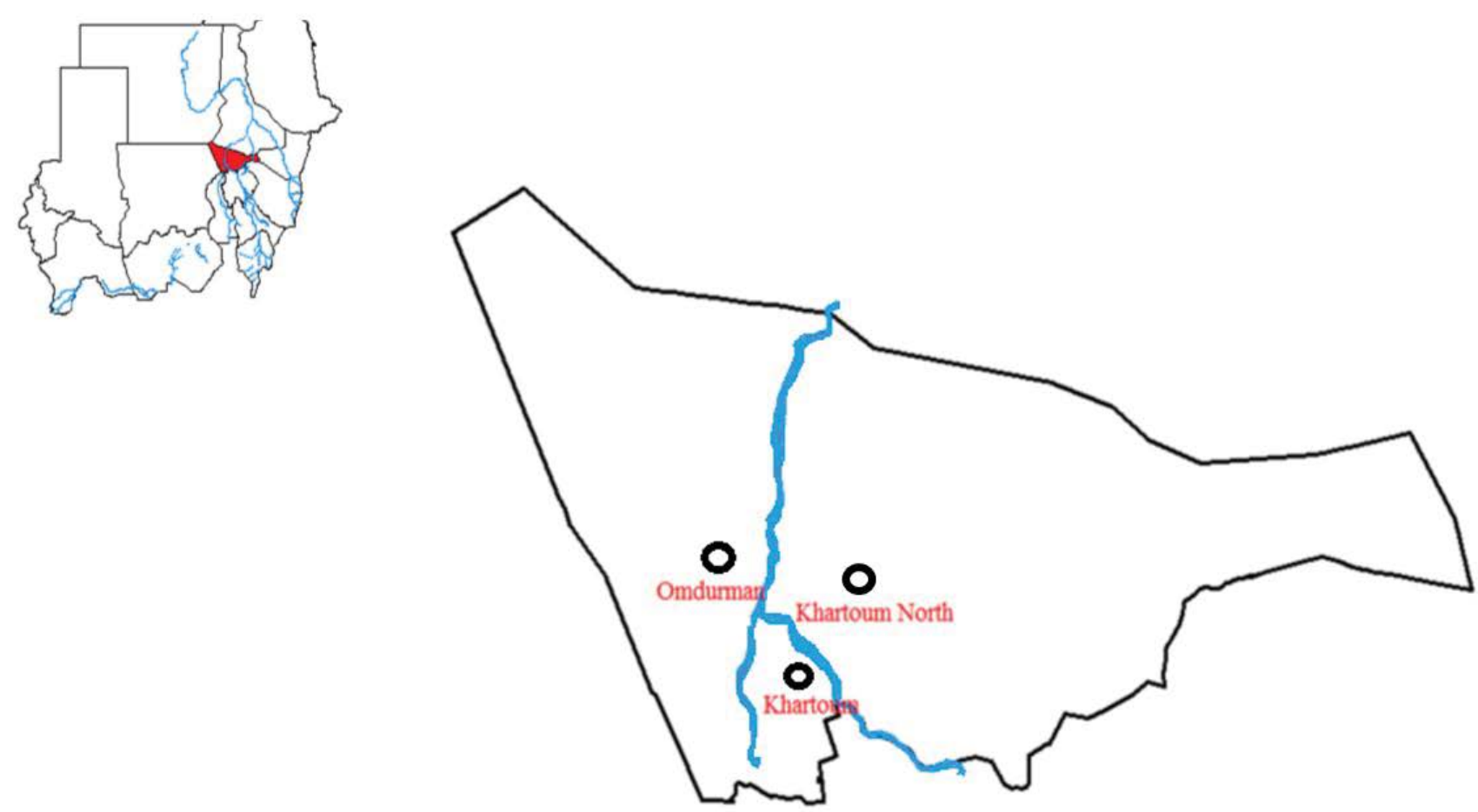

Figure 1: Map shows the study sites; Khartoum, Khartoum North and Omdurman. 
labeled tubes were transported to the laboratory at the Department of Parasitology and Medical Entomology, Faculty of Medical Laboratory Sciences, University of Khartoum, Sudan and kept in a $-20^{\circ} \mathrm{C}$ freezer for morphological identification and parasitological testing.

\section{Morphological identification of the house flies}

Identification of flies was performed using morphologic criteria to the family taxon level following the identification keys $[8,19]$.

\section{Isolation of intestinal parasites from external sur- faces of $M$. domestica flies}

House flies in the collection tubes were removed from the freezer, and shaken vigorously inside the wash fluid (normal saline) to dislodge parasites from external surfaces of the flies. The washed fluids were then transferred into a conical glass test tube and centrifuged at $3000 \mathrm{rpm}$ for 3 minutes. Sediments were examined under light microscope using 10X for examination of parasite and 40X for identification. Slides were prepared in three replicates for each sample to increase the chance of parasite detection. The stages of parasites were identified based on morphological details as described by Soulsby [20] and identified specimens confirmed by two experts from the Department of Parasitology and Medical Entomology, Faculty of Medical Laboratory Sciences, University of Khartoum.

\section{Results}

The total number of house flies, $M$. domestica identified was 684 . A variety of species of both protozoan and metazoan parasites were recovered from within $2.9 \%$ (20 out of 684) of house flies collected from the different sites (Table 1 ).

Most of the house flies ( $n=300 ; 43.9 \%)$ were collected from Khartoum city, followed by Khartoum North ( $\mathrm{n}$ $=260 ; 38.01 \%)$, while the least number of flies $(n=124$; 18.1\%) were collected from Omdurman city (Table 1). A variety of species of both protozoan and metazoan par- asites were detected (Table 1). Identified species of the detected intestinal parasites transmitted by the house flies include: Entamoeba coli, Entamoeba histolytica/ dispar, Giardia lamblia, Hymenolepis nana and Taenia species (Figure 2). Only 5\% (1 out of 20) infected house flies was found to carry more than one type of parasites (Table 1 and Table 2).

The most prevalent parasite was the cyst of $E$. coli (33.3\%; $\mathrm{n}=7)$, followed by $E$. histolytica/dispar cyst $(19 \% ; n=4)$, flagellates of $G$. lamblia $(19 \% ; n=4)$, cyst of G. lamblia (14.3\%; $n=3)$, ova of H. nana $(9.5 \% ; n=2)$ and ova of Taenia sp. $4.8 \%(\mathrm{n}=1)$ respectively (Table 2$)$.

\section{Discussion}

Musca domestica, is one of the most common fly species found worldwide. It has been considered as vector of more than 100 pathogens [1]. In this study, more protozoan infections were recorded than metazoan infections. This is in agreement with the result of Al-Diwaniya Province, Iraq [5] and Maiduguri metropolis in Nigeria [1]. Majority of the identified intestinal parasites in this study originated from human faeces [2]. This was also observed in Egypt [1], in areas where people defecated in open areas. The possibility of transmission of parasites remains a cause for concern wherever infestation of parasites in the community is high, particularly in those areas where open field defecation is regularly practiced [16].

The role of house flies in the spreading of gastrointestinal infections is dependent on their habit of visiting faecal material for oviposition. The house flies may drop these parasites on unprotected food and utensils, thereby facilitating the entry of these parasites in human body [4]. The spread of such infectious agents is directly dependent on the seasonal abundance of house flies, availability of faeces, presence of pathogens in the faecal material, pathogen carrying capacity of each house fly, and access of house flies to unprotected food and utensils [6].

Table 1: Number of collected house flies and detected intestinal parasites that infested slaughterhouses in central markets of Khartoum state, Sudan.

\begin{tabular}{|l|l|l|l|}
\hline Location & $\begin{array}{l}\text { Total number of house flies } \\
\text { examined }\end{array}$ & $\begin{array}{l}\text { Total number of infected } \\
\text { flies }\end{array}$ & $\begin{array}{l}\text { Total number of parasite } \\
\text { species found }\end{array}$ \\
\hline Khartoum & $300(43.86 \%)$ & $14(70 \%)$ & $5(62.5 \%)$ \\
\hline Khartoum North & $260(38.01 \%)$ & $6(30 \%)$ & $3(37.5 \%)$ \\
\hline Omdurman & $124(18.13 \%)$ & 0 & 0 \\
\hline Total & 684 & 20 & 8 \\
\hline
\end{tabular}

Table 2: Identified species of intestinal parasites and their percentages in the house fly vectors.

\begin{tabular}{|l|l|l|l|l|}
\hline Location & Detected intestinal parasites & Stage & Number & Percentage (\%) \\
\hline Khartoum; Khartoum North & Entamoeba histolytica/dispar & cyst & 4 & 19 \\
\hline Khartoum & Giardia lamblia & flagellate & 4 & 19 \\
\hline Khartoum; Khartoum North & Giardia lamblia & cyst & 3 & 14.3 \\
\hline Khartoum & Hymenolepis nana & ova & 2 & 9.5 \\
\hline Khartoum & Taenia sp. & ova & 1 & 4.8 \\
\hline Khartoum; Khartoum North & Entamoeba coli & cyst & 7 & 33 \\
\hline
\end{tabular}



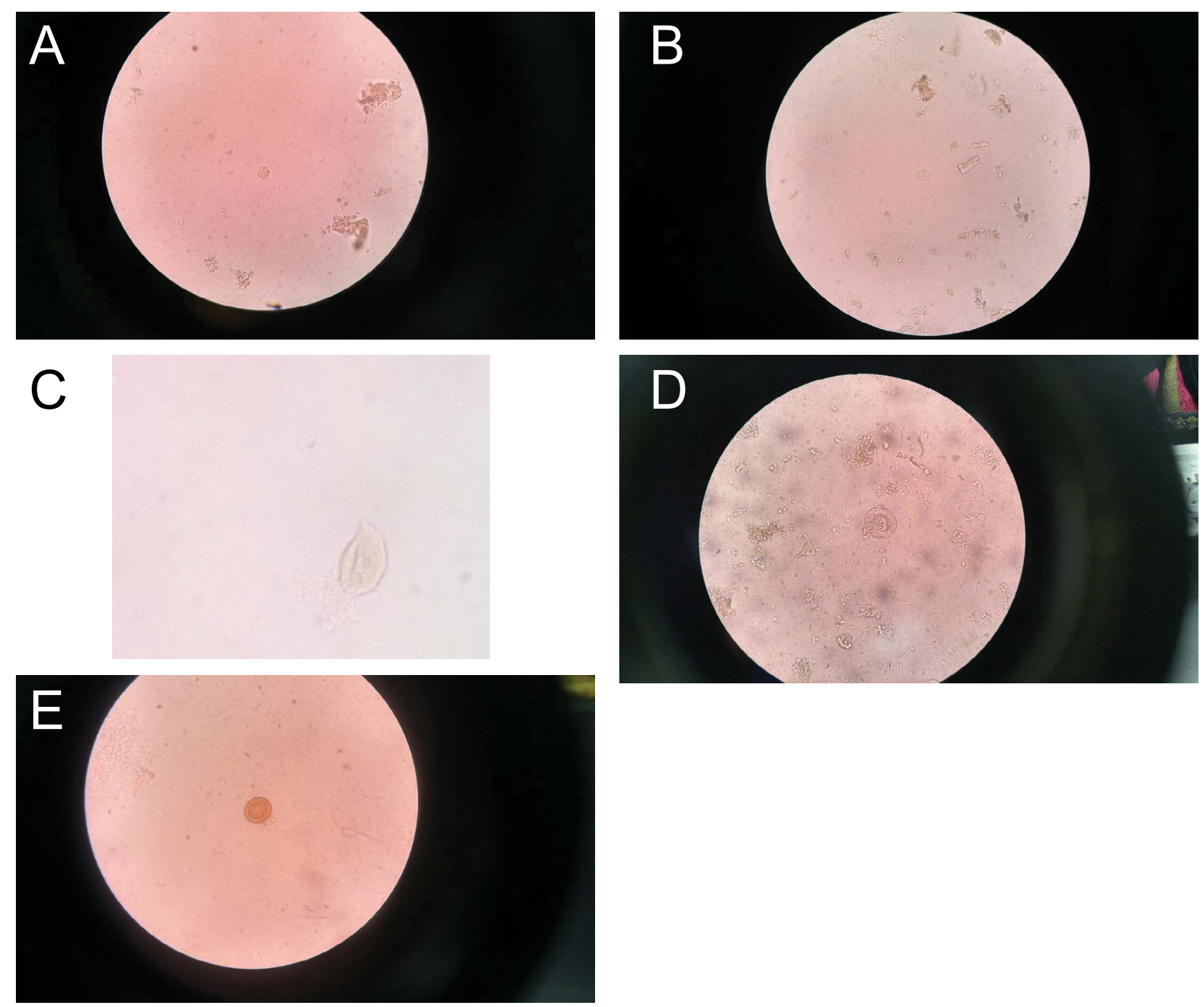

Figure 2: Intestinal parasites isolated in this study. A) Entamoeba coli cyst; B) E. histolytica/dispar cyst; C) Giardia lamblia cyst; D) Hymenolepis nana ova; E) Taenia sp. ova (wet mount X40).

Only $2.9 \%$ of house flies were found infected with intestinal parasites in this study. Khartoum city has shown the highest prevalence while Omdurman was free of parasites. The reasons for the zero number of infected flies from Omdurman could be due to: the small number of collected flies; failure to recover the parasite from the flies once picked-up or reduced access of flies to human excreta [16]; also, it might be due to the effect of high temperature on shortening the life span of the house fly and/or limiting its movement to areas of optimal ambient temperature [21].

Parasitic studies of randomly collected flies from slaughterhouses environment may provide an epidemiological tool for monitoring an existing sanitary condition and the intestinal parasites circulating in the area.

\section{Conclusions}

The findings of this study have demonstrated that house flies are potential vectors of intestinal parasites in Khartoum state and possibly other parts of Sudan. Detection of intestinal parasites circulating withinthe Khartoum state house fly population means there is a need to improve the hygiene, sanitation, and the fly proofing in the vulnerable communities, particularly in the slaughterhouses and food processing facilities to control these diseases in addition to other control measures.

\section{Acknowledgements}

The authors wish to thank the workers at slaughterhouses for their acceptance to collect the flies, and the staff of the Department of Parasitology and Medical Entomology for using their laboratory to conduct this work.

\section{References}

1. Balla H, Usman $Y$, Muhammad A (2014) The role of housefly (Musca domestica) in mechanical transmission of intestinal parasites in Maiduguri metropolis, northeastern Nigeria. J Nat Sci Research 4: 60-66.

2. Iqbal W, Malik M, Sarwar M, Azam I, Iram N, et al. (2014) Role of housefly (Musca domestica, Diptera; Muscidae) as a disease vector; A review. Journal of Entomology and Zoology Studies 2: 159-163.

3. Barreiro C, Albano H, Silva J, Teixeira P (2013) Role of flies 
as vectors of foodborne pathogens in rural areas. ISRN Microbiology 2013: 1-7.

4. Manandhar R, Gokhale S (2017) Are houseflies still important vector of gastrointestinal infections? J Bacteriol Parasitol 8: 318.

5. Al-Aredhi H (2015) Role of house flies (Musca domestica) as vector host for parasitic pathogens in Al-Diwaniya Province/Iraq. International Journal of Science and Research 4: 1961-1965.

6. Oghale O, Ebube C, Oluchi U (2013) Parasitic load on Musca domestica (Dipthera: Muscidae) from different synanthropic environments in Umuahia metropolis. Journal of Public Health and Epidemiology 5: 309-312.

7. Masroor Alikhan, Khalid Al Ghamdi, Jazem A Mahyoub, Naima Alanazi (2016) Public health and veterinary important flies (order: Diptera) prevalent in Jeddah Saudi Arabia with their dominant characteristics and identification key. Saudi Journal of Biological Sciences.

8. Lau W, Mahsuri S, Kamis S, Sarkowi F, Tan M, et al. (2016) Occurrence of synanthropic flies in Tasek Bera Ramsar site, Pahang. Journal of Wildlife and Parks 31: 21-38.

9. Kassiri H, Zarrin M, Veys-Behbahani R, Faramarzi S, Kasiri A (2015) Isolation and identification of pathogenic filamentous fungi and yeasts from adult house fly (Diptera: Muscidae) captured from the hospital environments in Ahvaz City, Southwestern Iran. J Med Entomol 52: 1351-1356.

10. Collinet-Adler S, Babji S, Francis M, Kattula D, Premkumar PS, et al. (2015) Environmental factors associated with high fly densities and diarrhea in Vellore, India. Appl Environ Microbiol 81: 6053-6058.

11. Graczyk T, Grimes B, Knight R, Da Silva A, Pieniazek N, et al. (2003) Detection of Cryptosporidium parvum and Giardia lamblia carried by synanthropic flies by combined fluorescent in situ hybridization and a monoclonal antibody. Am J Trop Med Hyg 68: 228-232.
12. Echeverria P, Harrison B, Tirapat C, McFarland A (1983) Flies as a source of enteric pathogens in a rural village in Thailand. Appl Environ Microbiol 46: 32-36.

13. Lindsay D, Stewart W, Watt J (1953) Effect of fly control on diarrheal disease in an area of moderate morbidity. Public Health Rep 68: 361-367.

14. Szostakowska B, Kruminis-Lozowska W, Racewicz M, Knight R, Tamang L, et al. (2004) Cryptosporidium parvum and Giardia lamblia recovered from flies on a cattle farm and in a landfill. Appl Environ Microbiol 70: 3742-3744.

15. Watt J, Lindsay DR (1948) Diarrheal disease control studies; effect of fly control in a high morbidity area. Public Health Rep 63: 1319-1333.

16. Fotedar R, Banerjee U, Singh S, Shriniwas, Verma AK (1992) The housefly (Musca domestica) as a carrier of pathogenic microorganisms in a hospital environment. $J$ Hosp Infect 20: 209-215.

17. Abuelmaali S, Elaagip A, Basheer M, Frah E, Ahmed F, et al. (2013) Impacts of agricultural practices on insecticide resistance in the malaria vector Anopheles arabiensis in Khartoum state, Sudan. PLoS One 8: e80549.

18. Abdel Hamid M, Eljack I, Osman M, Elaagip A, Muneer M (2015) The prevalence of Hymenolepis nana among preschool children of displacement communities in Khartoum state, Sudan: A cross-sectional study. Travel Med Infect Dis 13: $172-177$.

19. Dodge $H$ (1953) Diptera: Pictorial key to principal families of public health importance. Department of Health, Education and Welfare, Atlanta, Ga, USA.

20. Soulsby E (1982) Helminths, arthropods and protozoa of domesticated animals. English language book society, Baillere Tindall, London, 192.

21. Ragland SS, Sohal RS (1975) Ambient temperature, physical activity and aging in the housefly, Musca domestica. Exp Gerontol 10: 279-289. 